\title{
ADULT CEREBELLAR MEDULLOBLASTOMA
}

\section{$\mathrm{CT}$ and MRI findings in eight cases}

\author{
Arnolfo de Carvalho Neto', Emerson L. Gasparetto ${ }^{2}$, Sérgio E. Ono ${ }^{3}$, \\ Guilherme A. Bertoldi', André F. Gomes ${ }^{5}$
}

\begin{abstract}
Medulloblastoma is a brain tumor of neuroepithelial origin, which represents 15 to $30 \%$ of all pediatric brain tumors, and less than $1 \%$ of CNS adult neoplasms. We report the imaging findings of 8 adult patients with medulloblastoma. The mean age was 35 years, ranging from 20 to 65 years, and the male:female rate was 3:5. The tumors were predominantly lateral (63\%), hyperdense on CT scans ( $83 \%)$, and on the MRI, hypointense on T1 (100\%) and hyperintense on T2 (80\%) weighted images. It was seen intratumoral necrosis and cysts in six cases and calcifications in three. Hydrocephalus was observed in 5 cases and brain stem invasion in four. The imaging findings of medulloblastomas in adults are different of those in child, and also nonspecific. Although these tumors are uncommon in adults, they must be considered in the differential diagnosis of cerebellar masses in the posterior fossa of this age group.
\end{abstract}

KEY WORDS: medulloblastoma, adults, computed tomography, magnetic resonance imaging.

\begin{abstract}
Meduloblastoma cerebelar em adultos: achados de TC e RM em oito casos
RESUMO - O meduloblastoma é um tumor de origem neuroepitelial, que representa entre 15 e $30 \%$ dos tumores cerebrais em crianças e menos de $1 \%$ das neoplasias intracranianas em adultos. Apresentamos os achados de imagem de 8 pacientes adultos com meduloblastoma. A média de idade foi 35 anos, variando entre 20 e 65 anos, e a relação homem:mulher foi 3:5. Os tumores foram predominantemente laterais (63\%), hiperdensos na tomografia computadorizada (83\%), e, na ressonância magnética, hipointensos nas imagens ponderadas em T1 (100\%) e hiperintensos nas ponderadas em T2 (80\%). Necrose e cistos intratumorais foram observados em seis casos e calcificações em três. Cinco pacientes apresentavam hidrocefalia e quatro tinham invasão neoplásica do tronco cerebral. Os achados de imagem dos meduloblastomas em adultos são inespecíficos e diferentes daqueles que acometem crianças. Apesar destes tumores serem incomuns em adultos, eles devem sem considerados no diagnóstico diferencial de massas cerebelares na fossa posterior de pacientes neste grupo etário.
\end{abstract}

PALAVRAS-CHAVE: meduloblastoma, adulto, tomografia computadorizada, ressonância magnética.

Medulloblastoma accounts for $4-8 \%$ of primitive intracranial tumors of neuroepithelial origin. It represents 15 to $30 \%$ of all pediatric brain tumors and it is a rare entity in the adult age accounting to less than $1 \%$ of brain tumors in this age group. The peak of occurrence is between 5-7 years of age, with $70 \%$ of them occurring under 16 years. At the presentation, truncal ataxia, intracranial hypertension syndrome, lethargy, headache, and morning vomiting are the most frequent symptoms ${ }^{1-3}$.

On CT scans, these tumors are described as a welldefined, hyperdense and homogeneous midline mass with marked enhancement after contrast injection. The MRI frequently shows a well-defined posterior fossa tumor, which presents low signal on T1 and high signal on T2 weighted images, with marked enhancement after gadolinium injection. When comparing the imaging findings of medulloblastomas in children and adults, there are some contradictions, with several authors reporting the same pattern on this two populations, and others showing different imaging finding $\mathrm{s}^{4-7}$.

We present the CT and MRI findings of 8 patients over 16 years of age with cerebellar medulloblasto-

\footnotetext{
${ }^{1}$ Assistant Professor of the Discipline of Diagnostic Radiology, University of Paraná, Curitiba PR, Brazil (UFPR); ${ }^{2}$ Resident of the Diagnostic Radiology Section, Hospital de Clínicas, UFPR; ${ }^{3}$ Medical Student of the UFPR School of Medicine; ${ }^{4}$ Substitute Professor of the Discipline of Diagnostic Radiology, UFPR; ${ }^{5}$ Attending of the DAPI - Diagnóstico Avançado Por Imagem - Curitiba PR, Brazil.
}

Received 31 July 2002, received in final form 11 November 2002. Accepted 13 November 2002.

Dr. Arnolfo de Carvalho Neto - Serviço de Radiologia Médica, Hospital de Clínicas, UFPR - Avenida General Carneiro 181 - $80060-900$ Curitiba PR - Brasil. E-mail: arnolfo.carvalho@avalon.sul.com.br 


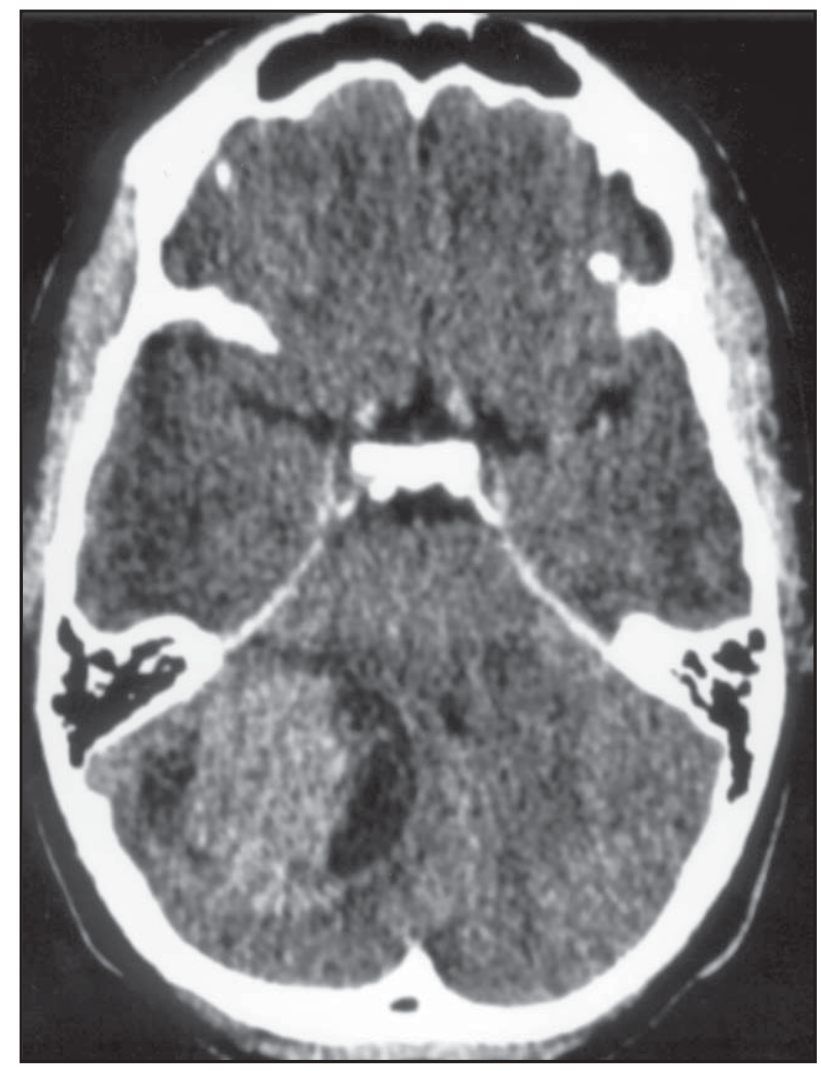

Fig 1. Axial CT scan before contrast injection showing a hyperdense right cerebellar mass, with a hypodense cystic portion.

mas diagnosed since 1988 at the Hospital de Clínicas of the University of Paraná.

\section{METHOD}

We reviewed retrospectively the patients over 16 years of age with medulloblastoma diagnosed between 1988 and 2002 at the Hospital de Clínicas of the University of Paraná. All films (CT scan and MRI) of these patients were selected and reviewed by a neuroradiologist (ACN). The evaluation consisted of observation of tumor location, presence of necrosis and cysts, hydrocephalus, calcifica- tions, invasion of the brain stem and density (CT)/intensity (MRI) pattern before and after IV contrast injection.

\section{RESULTS}

The mean age in our serie was 35 years, ranging from 20 to 65 years. The sex distribution was five females and three male patients. Three patients underwent CT scan and MRI, three only CT scan and in two patients only MRI was performed. The six CT scans showed that five (83\%) were hyperdense and one hypodense before IV contrast injection. The MRI showed tumors predominantly hypointense on T1 $(100 \%, n=5)$ and hyperintense on T2 $(80 \%, n=4)$ weighted images. The tumors were most commonly located on the cerebellar hemispheres (63\%), and only three were vermian tumors. It was seen intratumoral necrosis and cysts in six of them and calcifications in three cases. Hydrocephalia was present in 4 patients and invasion of the brain stem was observed in 4 cases (Figs 1-6). The data related to these images are presented in Tables 1 and 2 .

\section{DISCUSSION}

Medulloblastomas arise from nests of germinal cells, which proliferate in the neuroepithelial roof of the fourth ventricle in fetal life and migrate upwards and laterally ${ }^{5}$. There are two other theories trying to explain the histogenesis of this tumor ${ }^{1,3}$. One suggests that it originates from the external granular layer of the cerebellum and the most recent theory suggests two possible origins: the classic medulloblastoma is derived from the fourth ventricle and the desmoplastic medulloblastoma from the external granular layer ${ }^{2,8}$.

This malignant cerebellar tumor represents 15 to $30 \%$ of all pediatric brain tumors ${ }^{2,4,7-10}$ with an incidence of 0.5 per 100.000 per year $^{1}$ and accounts for

Table 1. Description of the CT scan findings of 6 adult patients with medulloblastoma.

\begin{tabular}{ccccccccc}
\hline Case & $\begin{array}{c}\text { Age } \\
\text { years }\end{array}$ & Sex & Location & $\begin{array}{c}\text { Necrosis } \\
\text { / Cysts }\end{array}$ & Hydrocephalus & $\begin{array}{c}\text { Calcifications } \\
\text { Density }\end{array}$ & $\begin{array}{c}\text { Brain stem } \\
\text { invasion }\end{array}$ \\
\hline 1 & 65 & F & RCH & yes & no & no & hypodense & no \\
4 & 20 & F & vermis & yes & yes & yes & hyperdense & yes \\
5 & 24 & F & RCH & yes & yes & no & hyperdense & yes \\
6 & 29 & M & vermis & yes & no & no & hyperdense & yes \\
7 & 22 & M & LCH & yes & yes & yes & hyperdense & yes \\
8 & 48 & M & vermis & no & yes & yes & hyperdense & no \\
\hline
\end{tabular}

LCH, left cerebellar hemisphere; $\mathrm{RCH}$, right cerebellar hemisphere. 


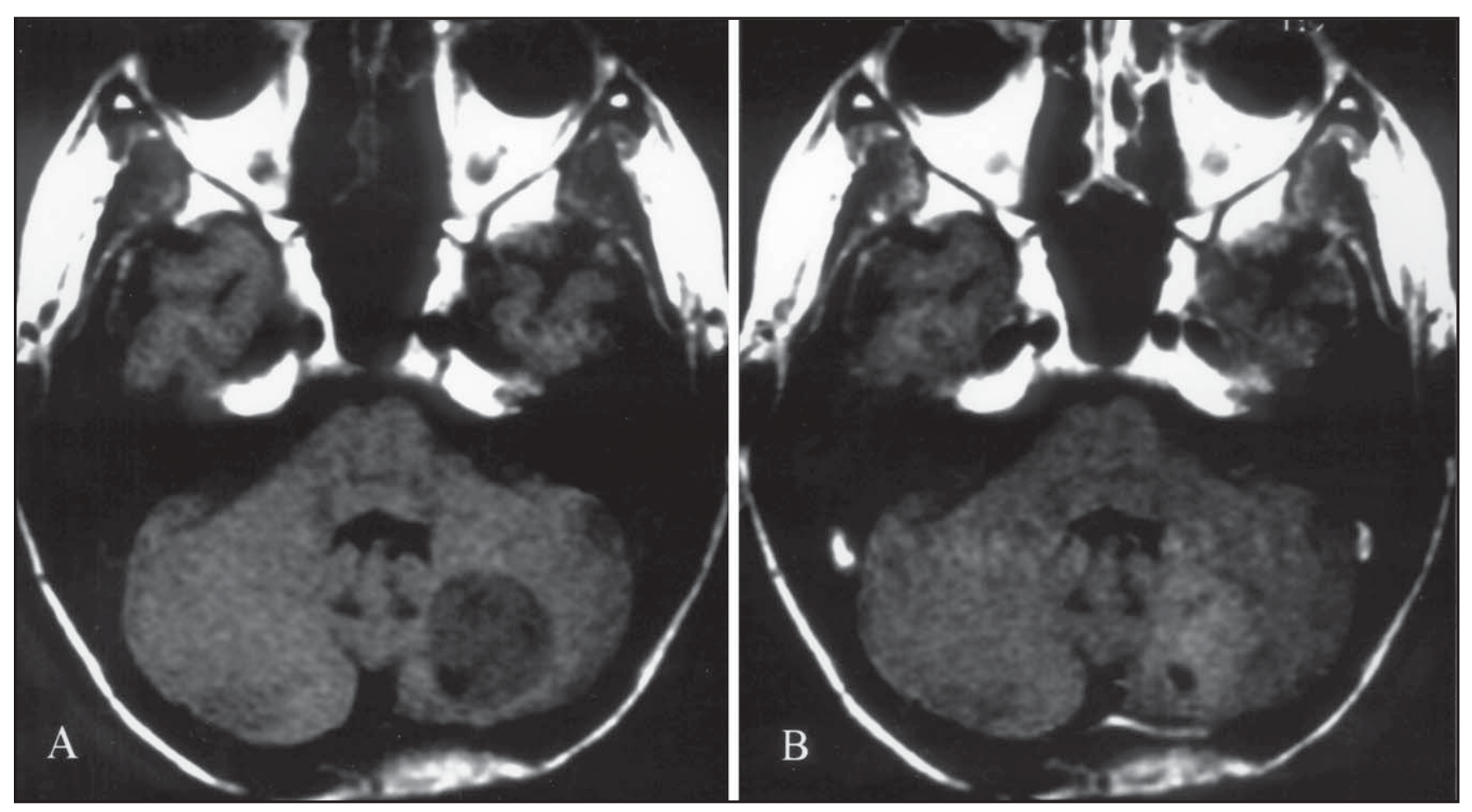

Fig 2. (A) Axial T1 weighted MRI before contrast injection revealing a hypointense homogeneous left cerebellar mass. (B) After gadolinium injection, the lesion showed mild enhancement.

$4-8 \%$ of primitive intracranial tumors of neuroepithelial origin ${ }^{10}$. Medulloblastomas are rare in adults, accounting for less than 0.005 per 100000 annually ${ }^{8}$ and representing less than $1 \%$ of central nervous system tumors in this age group $p^{2,4,7,10}$. There is a predominance of males, with a male:female distribution of $2: 1^{5,9,11}$. Its peak of incidence is around 5 to 7 years of age, $70 \%$ of them occurring under 16 years ${ }^{1,9}$. Al-Mefty et al. ${ }^{1}$ reviewed 75 cases in Saudi Arabia and reported a similar number, with $79 \%$ occurring in children. In adulthood, $80 \%$ occur between 21 and 40 years. The mean age of our study group was 35 years, and we observed predominance of female patients $(63 \%)^{7}$.
The imaging findings of cerebellar medulloblastoma in children is well established on CT images as a well defined, hyperdense and homogeneous midline mass with marked enhancement after IV contrast injection ${ }^{4,5,11}$. Nevertheless, atypical features, which include calcification, cystic or necrotic regions, ill-defined margins and lack of enhancement, should not be considered against the diagnosis of medulloblastoma in the first decade of life ${ }^{5}$.

Several authors stressed the imaging features of medulloblastomas in adult patients ${ }^{2,4,7,8,10}$. Hubbard et al. reported the Mayo Clinic casuistic and found $62 \%$ of these tumors located in the cerebellar hemispheres ${ }^{4}$. Bourgouin et al. studied 28 cases of medul-

Table 2. Description of the MRI findings of 5 adult patients with medulloblastoma.

\begin{tabular}{|c|c|c|c|c|c|c|c|c|}
\hline Case & Age & $\begin{array}{c}\text { Sex } \\
\text { years }\end{array}$ & Location & $\begin{array}{c}\text { Necrosis } \\
\text { / Cysts }\end{array}$ & Hydrocephalus & T1 signal & T2 signal & $\begin{array}{c}\text { Brain stem } \\
\text { invasion }\end{array}$ \\
\hline 2 & 42 & $\mathrm{~F}$ & $\mathrm{LCH}$ & yes & no & hypointense & isointense & no \\
\hline 3 & 32 & $\mathrm{~F}$ & $\mathrm{RCH}$ & no & yes & hypo/hyperintense & iso/hyperintense & no \\
\hline 6 & 29 & M & vermis & yes & no & hypointense & hyperintense & yes \\
\hline 7 & 22 & M & $\mathrm{LCH}$ & yes & yes & hypointense & hyperintense & yes \\
\hline 8 & 48 & M & vermis & no & yes & hypointense & hyperintense & no \\
\hline
\end{tabular}

$\mathrm{LCH}$, left cerebellar hemisphere; $\mathrm{RCH}$, right cerebellar hemisphere. 


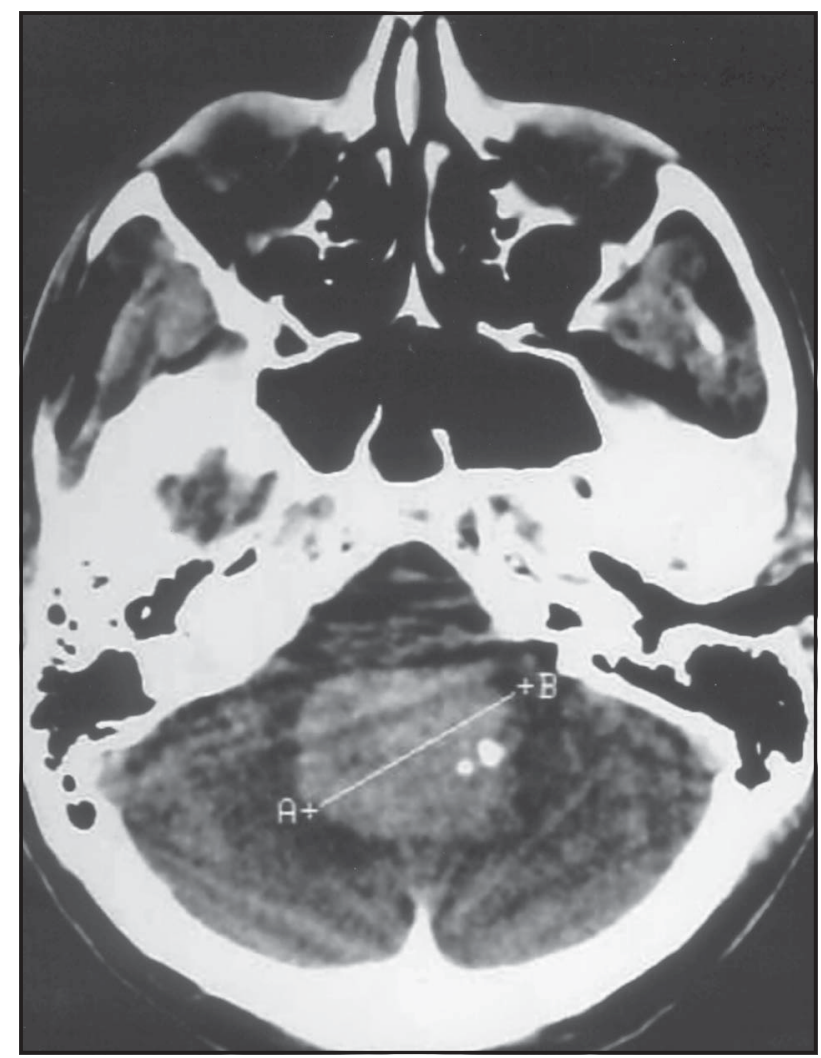

Fig 3. Axial CT scan showing a midline cerebellar mass, with enhancement after contrast injection. Areas of calcification are also observed.

loblastoma in adults and observed a similar percentage of vermian $(50 \%)$ and lateral $(50 \%)$ tumors 4 . Maleci et al. compared the imaging features of adult and children with medulloblastoma and found that $50 \%$ of the lesions were lateral in the first group, compared to $30 \%$ in the second. In our study we found predominance of lateral tumors $(63 \%)^{7}$.

Hubbard et al. observed that vermian medulloblastomas closely resembled the childhood tumors, and paramedian lesions have the same characteristics of the midline tumors in density and contrast enhancement pattern. Regarding the lateral tumors, they found a pattern slight different from the children tumors, with hyperdensity and contrast enhancement being more marked.Thery also concluded that coronal CT scans and MRI were more helpful in defining the intra-axial location of the cerebellar medulloblastoma than were axial CT slices $^{5}$.

All the studies concerning medulloblastomas in adult patients had concluded that hyperdensity is a common feature in these tumors ${ }^{2,4-7,10}$. Hubbard et al. found hyperdense lesions in $66 \%$ of the patients and in the Bourgouin et al casuist all the tumors were hyperdense before intravenous contrast injection? ${ }^{2}$.

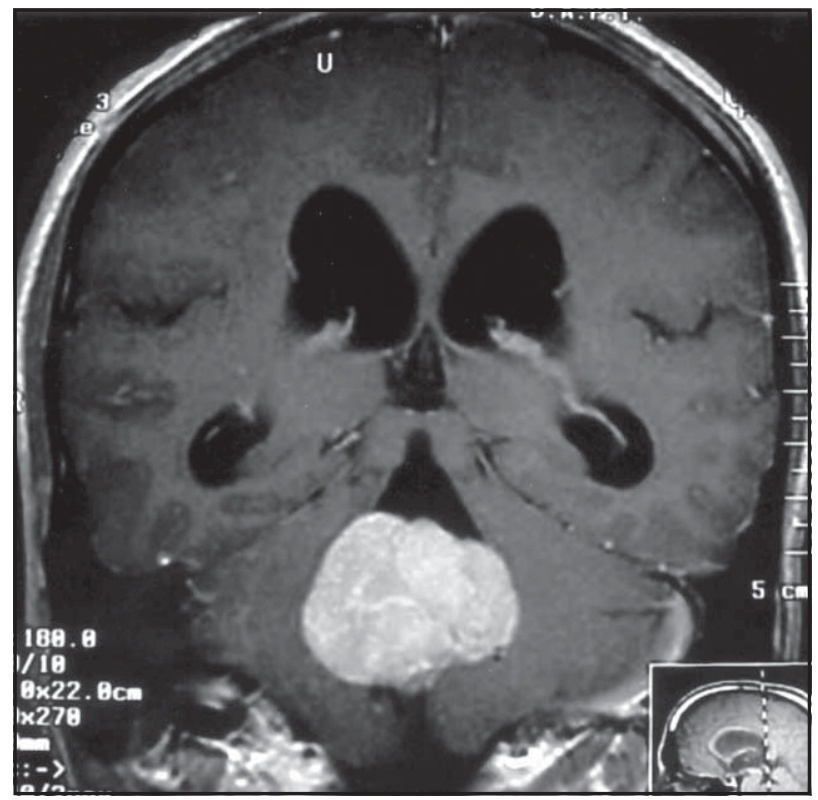

Fig 4. Coronal T1 weighted MRI after contrast injection revealing an enhanced midline cerebellar mass. Hydrocephalus is also observed.

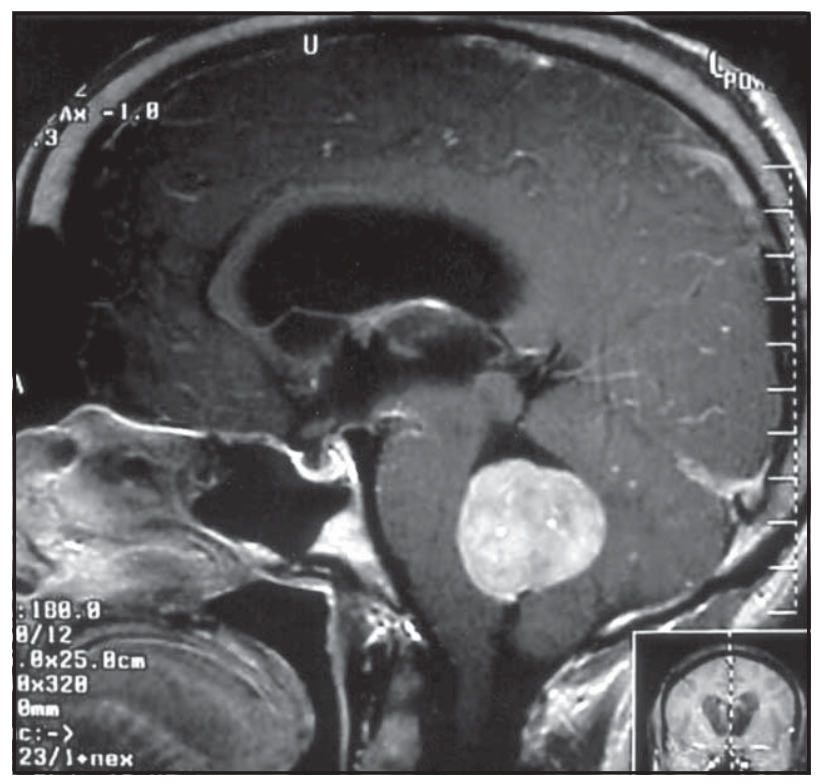

Fig 5. Sagittal T1 weighted MRI after contrast injection showing a midline cerebellar mass with posterior compression of the brain stem.

Maleci et al. observed on CT scans that $89 \%$ of the medulloblastomas were hyperdense in the adults, compared to $63 \%$ in the children. In our casuistics $83 \%$ (5 of 6 ) of the medulloblastomas presented as hyperdense lesions on CT scans ${ }^{7}$.

Atypical findings in medulloblastomas of adult patients were also stressed by Bourgouin et al. ${ }^{2}$. Low density areas, consistent with intratumoral cysts and necrosis were seen in 23 patients (82\%), calcifications 


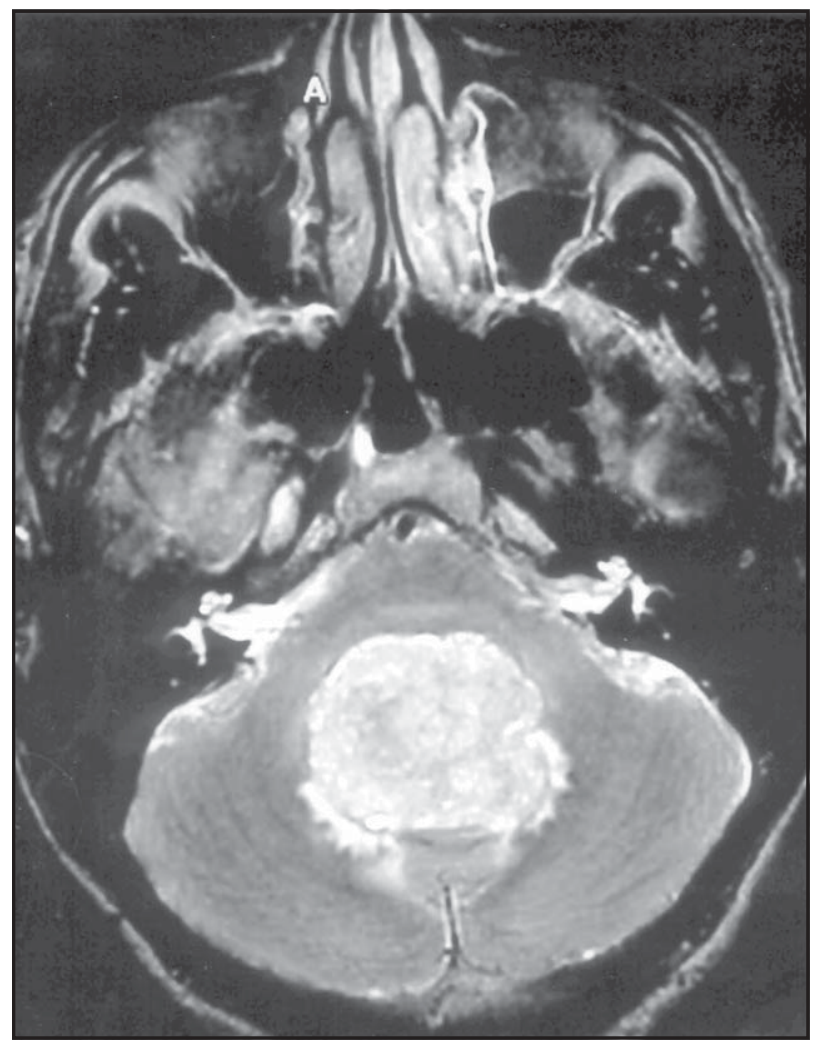

Fig 6. Axial T2 weighted MRI revealing a hyperintense midline cerebellar mass.

were observed in 2 patients (7\%) and edema was present in 21 tumors (75\%). Hydrocephalus of various degrees of severity was seen in 26 patients (93\%). These authors concluded that medulloblastoma in adults shows a high prevalence of intratumoral low-density areas caused by cystic and necrotic degeneration. The prevalence of calcifications, ede$\mathrm{ma}$, hydrocephalus and the size of tumors are comparable in adults and children. In our casuistics, low density areas compatible with necrosis and/or cysts were observed in $75 \%$ of the tumors $(n=6)$, hydrocephalus in $63 \%(n=5)$ and calcifications in three of six cases $(50 \%)$.

Regarding the MRI features, Koci et al. ${ }^{6}$ evaluated 12 MRI of adult patients with medulloblastoma. Preoperative T1 weighted images showed hypointense tumors in 8 cases $(67 \%)$, isointense to gray matter in three cases (25\%) and a hyperintense mass in one case. T2-weighted images revealed five hyperintense tumors (42\%), three slightly hyperintense (25\%), and three isointense tumors (25\%); one lesion had a dominant markedly hyperintense cystic component. Nine patients presented enhancement after gadolinium injection. Five of our patients underwent MRI and all presented with hypointense signal on $\mathrm{T} 1$ and $80 \%$ showed hyperintense signal on $\mathrm{T} 2$ weighted images.

A literature review regarding medulloblastomas in adults shows that the CT scans do not follow a consistent pattern like the well defined, homogeneous, hyperdense, median mass seen in the medulloblastoma of children. The tumors in adults have a variety of presentations, but a tendency of being more frequently located laterally and presenting with atypical images of necrosis and cysts is noted. Enhancement on CT scans is not always seen after contrast injection. For these reasons, the differential diagnosis of masses in the posterior fossa of an adult must include the hypothesis of a medulloblastoma.

\section{REFERENCES}

1. Al-Mefty O, Jinkins JR, El-Senoussi M, et al. Medulloblastomas: a review of modern management with a report on 75 cases. Surg Neurol 1985; 24:606-624.

2. Bourgouin PM, Tampieri D, Grahovac SZ, Léger C, Del Carpio R, Melançon D. CT and MR imaging findings in adults with cerebellar medulloblastomas: comparison with findings in children. AJR 1992; 159:609-612.

3. Giangaspero F, Bigner S H, Kleihues P, Pietsch T, Trojanowski JQ. Medulloblastoma. In Kleihues P, Cavanee WK (eds). World Health Organization classification of tumours pathology and genetics: Tumours of the nervous system. 2.Ed. Oxford: Oxford Univ Press, 2000:123-127.

4. Haie-Meder C, Song PY. Medulloblastoma: differences in adults and children: regarding Frost et al., IJROBP 32:951-957; 1995 and Prados et al., IJROBP 32:1145-1152; 1995. Int J Radiation Oncology Biol Phys 1995;32:1255-1257.

5. Hubbard JL, Scheithauer BW, Kispert DB, et al. Adult cerebellar medulloblastomas: the pathological, radiographic, and clinical disease spectrum. J Neurosurg 1989;70:536-544.

6. Koci M, Chiang F, Mehringer CM, et al. Cerebellar medulloblastoma: imaging features with emphasis in MR findings. AJNR 1993;14:929-939.

7. Maleci A, Cervoni L, Delfini R. Medulloblastoma in children and in adults: a comparative study. Acta Neurochir 1992;119:62-67.

8. Reis JS Filho, Gasparetto EL, Faoro LN, et al. Medulloblastomas: clinical, epidemiological and pathological findings in 28 cases. Arq Neuropsiquiatr 2000;58:76-80.

9. Shandu A, Kendall B. Computed tomography in management of medulloblastomas. Neuroradiology 1987;29:444-452.

10. Juhl JH, Crummy AB, Kuhlman JE. Paul and Juhl's essentials of radiologic imaging. 2.Ed. Philadelphia: Lippincott Williams \& Wilkins, 1998:338-339.

11. Tortori-Donati P, Fondelli MP, Rossi A, et al. Medulloblastoma in children: CT and MRI findings. Neuroradiology 1996,38:352-359 